\title{
ALUNOS-MONITORES: UMA EXPERIÊNCIA EM FUNDAMENTOS DE ENFERMAGEM
}

\section{Maria Romana Friedlander*}

FRIEDLANDER, M. R. Alunos-monitores: uma experiência em Fundamentos de Enfermagem, Rev. Esc. Enf. USP, Sðo Paulo, 18(2):1 13-120, 1984.

Säo descritos os resultados da utilização de três alunos, de classes mais adiantadas, como monitores na disciplina Fundamentos de Enfermagem, durante os periodos letivos de 1981 e 1982, e é analisada a opinizo desses monitores e dos estudantes orientados por eles.

\section{INTRODUÇÃO}

O aluno - monitor ou, simplesmente, monitor é o estudante que, interessado em desenvolver-se, aproxima-se de uma disciplina ou área de conhecimento e junto a ela realiza pequenas tarefas ou trabalhos que contribuem para o ensino, a pesquisa ou o serviço de extensato à comunidade dessa disciplina. Tal atividade é realizada fora do horário das aulas, dentro de um limite de horas pré-estabelecido e, com freqüência, é compensado com um auxílio financeiro que contribui para a manutenção do estudante durante o período de formação superior.

A presença do monitor nos cursos de enfermagem nấo é inédita e são vários os autores que mencionam a sua atividade (HOGSTEL, 1976; BLOOM, 1978).

$\mathrm{Na}$ disciplina Fundamentos de Enfermagem os monitores podem desenvolver vários tipos de atividades tais como orientação e avaliação do progreso dos estudantes no Laboratório de Enfermagem, demonstraçóes individuais, treinamento de procedimentos, esclarecimento de trechos de leitura de maior dificuldade, discussão de certas adequaçð̃es práticas, indicaçăo de bibliografia especifica e assim por diante.

DONUHUE, LITZ, SCOTT (1976) utilizaram monitores na implantação de um Sistema Personalizado de Instrução em Tecnologia de Enfermagem.

- Enfermeira. Professor Assistente Doutor do Departamento de Enfermagem Médico Cinírgica da Escola de Enfermagem da USP - disciplina Fundanentos de Enfermagem, atualmente em exercicio na Universidade Estadual de Campinas. 
Esses autores resumem a opinifo dos estudantes sobre alunos-monitores em cinco itens:

- geralmente os monitores parecem estar bem preparados e são capazes de orientar os estudantes nos aspectos do curso com maior dificuldade de compreensăo;

- os monitores demonstram paciência no seu relacionamento com os estudantes;

- os estudantes sentem-se livres para discutir com os monitores quando acreditam ter base para tanto;

- os estudantes geralmente consideram satisfatória as demonstrações dos procedimentos realizados pelos monitores; e

- a maioria dos estudantes não utiliza o monitor como primeiro recurso para a aprendizagem dos procedimentos.

Por sua vez, os mesmos autores descrevem a avaliaçร̃o dos monitores sobre seu trabalho, por meio das seguintes generalizações:

- a monitoria é uma oportunidade de rever o conteúdo aprendido em ano anterior;

- é uma oportunidade de se relacionar com outros estudantes;

- a monitoria é uma experiência muito boa; $\mathrm{e}$

- é um meio de aumentar a renda.

Contudo, a monitoria também apresenta certas desvantagens que, sob o ponto de vista dos monitores, podem ser reunidas em dois itens:

- o desgaste do monitor com a contínua necessidade de encorajar os estudantes a prepararem-se para os testes; $\mathrm{e}$

- a quantidade de tempo dispendido torna-se exíguo principalmente durante o período de exames e provas.

Em face da oportunidade de utilizar monitores na disciplina de Fundamentos de Enfermagem da Escola de Enfermagem da Universidade de Săo Paulo, não podíamos deixar de experimentar e avaliar essa modalidade de atividade estudantil, cujas vantagens parecem suplantar as desvantagens. Portanto, este trabalho tem a finalidade de descrever essa experiência e os resultados da avaliação realizada pelos estudantes e pelos próprios monjtores.

\section{DESCRIÇÃO DA EXPERIÊNCIA}

No segundo semestre de 1980, a Escola de Enfermagem da USP rece- 
beu verba destinada à utilização de monitores no ano de 1981. A Comissão de Monitoria, constituída com o fim de elaborar as normas para a utilização desse benefício, estabeleceu que a disciplina Fundamentos de Enfermagem poderia utilizar três alunos monitores no período de março a julho de 1981, os quais, posteriormente (de agosto a dezembro), desenvolveriam a atividade junto à disciplina Enfermagem Médico-Cirúrgica I. Após a divulgação das diretrizes básicas formuladas por essa comissão, tais como objetivos, requisitos, critérios de seleção tipos de atividades a serem desenvolvidas pelos monitores e datas para os testes de seleção, candidataram-se 16 estudantes do terceiro e do quarto ano, portanto, com certa desenvoltura na execução dos procedimentos básicos de enfermagem, interessados na monitoria junto às disciplinas Fundamentos de Enfermagem e Enfermagem Médico-Cirúrgica I.

O planejamento e a implementação das provas e das normas para a selef̧ão dos trés alunos-monitores ficou sob a responsabilidade de uma professora da disciplina e de una docente de Enfermagem Médico-Cirúrgica I que tambern representou Fundamentos de Enfermagem junto a Comissa de Monitoria e responsabilizou-se pela coordenaça e avaliaçáo das atividades dos monitores.

A seleçæ̃o dos alunos-monitores constou de:

a. prova escrita com questóes sob a forma de situaçăo-problema, a cargo da disciplina Enfermagem Médico-Cirúrgica I;

b. prova prático-oral no Laboratório de Enfermagem versando sobre os princípios fundamentais e a execuça dos principais procedimentos básicos de enfermagem em manequins, a cargo da disciplina Fundamentos de Enfermagem;

c. entrevista individual efetuada pela professora de cada uma das disciplinas em questão, na qual foi levantado o interesse do estudante, seus conhecimentos de inglês, necessidades financeiras, características para lidar com iniciantes, disponibilidade de tempo e facilidade de se expressar e se relacionar.

Foram convocadas para a entrevista individual as seis candidatas que obtiveram valor acima de sete na média aritmética das notas das duas primeiras provas. Das seis alunas entrevistadas foram selecionadas três.

As atividades projetadas para serem desenvolvidas pelos alunos-monitores na disciplina Fundamentos de Enfermagem tiveram como diretriz a especificação da Comissão de Monitoria, que estabeleceu como objetivos da monitoria: auxiliar no ensino, na pesquisa e nos serviços de extensão à comunidade, visando desenvolver no aluno-monitor conhecimentos e habilidades na disciplina escolhida. Sob essa orientação a disciplina Fundamentos de Enfermagem selecionou as seguintes atividades: 
- acompanhamento de estudantes no Laboratório de Enfermagem, com a finalidade de contribuir para o ensino dos procedimentos básicos;

- auxiliar nos trabalhos de pesquisa da disciplina;

- atualizar a bibliografia específica dos assuntos de interesse da disciplina; e

- eventualmente, auxiliar no preparo de aulas ou na elaboração ou organização de material audio-visual.

Em conjunto com os três alunos-monitores foram definidos os horários de trabalho, a distribuição das atividades, as formas de comunicação com a docente responsável e o estilo de avaliação a ser levado a efeito após o período de monitoria.

Em 1982, considerando-se que os três monitores selecionados para 1981 ainda preenchiam os requisitos estabelecidos, já tinham adquirido experiência e continuavam interessados nessa atividade, foi repetido o período de monitoria.

\section{AVALIAÇĀO DA EXPERIÊNCIA}

Após dois anos de monitoria, cada um dos três alunos-monitores preencheu um instrumento de avaliação (em anexo) constituído por nove questões fechadas e quatro questōes abertas, que deram oportunidade para o monitor expressar sua opinião quanto às atividades desenvolvidas.

Os três alunos-monitcres foram unânimes em afirmar que tinha achado agradável a monitoria, que voltariam a ser monitores caso houvesse oportunidade, que a atividade de monitoria nâo havia prejudicado seu aproveitamento no curso e que havia satisfeito razoavelmente as expectativas de cada um; que se encontravam preparados para o desempenho das tarefas realizadas e que a monitoria thes havia dado razoável oportunidade para desenvolver a capacidade de ensinar e proporcionado bastante oportunidade para estabelecer relacionamento com estudantes de outras séries.

Dois alunos-monitores afirmaram que o tempo não poderia ser mais bem aproveitado em outras atividades e cutra indicou que talvez pudesse ser. Dois afirmaram que a atividade desempenhada contribuíra para reforçar seus conhecimentos, enquanto outro acholi que nâo houvera essa contribuição:

Quanto às tarefas de monitoria que lhes haviam parecido mais proveitosas para seu próprio desenvolvimento pessoal, foram citadas:

- as atividades didáticas no Laboratório de Erfermagem, pois $\mathrm{r} \in$ forçavam os conhecimentos; 
- a participação nas pesquisas uma vez que esta permitia a visão đa relação dos resultados dos dados com os objetivos da pesquisa; e

- o contato direto com outros estudantes pois permitiam um relacionamento agradável.

Como vantagens os monitores afirmaram que a monitoria proporciona:

- contato com alunos de outros anos;

- oportunidade de desenvolver a capacidade de ensinar;

- contato com novos conhecimentos na área dos procedimentos de enfermagem;

- reforço dos conhecimentos já adquiridos, tanto sobre a disciplina em questão como sobre a metodologia de pesquisa; e

- conhecimento dos recursos humanos e materiais da disciplina e dos problemas inerentes a organizaçăo e implementaça do ensino nessa área.

Os três alunos-monitores apontaram como desvantagens da atividade de monitor:

- pouca participaço do monitor no crescimento global do estudante;

- pouca oportunidade de participar do relacionamento interpessoal estudante-cliente; $\mathrm{e}$

- atividades de pesquis pouco exigentes e que nao requeriam muito raciocínio.

Os monitores, ao analisarem suas atividades, tentaram colaborar com sugestoes de ordem prática que favorecessem o aproveitamento de futuros monitores.

Por outro lado, os 32 estudantes que utilizaram a orientaçăo de monitores, 15 em 1981 e 17 em 1982, responderam a quatro questరes fechadas, cujos resultados podem ser observados na Tabela 1. Cabe acrescentar que essas quatro questoes fizeram parte de um instrumento mais amplo elaborado para outra investigaçæo. Por esse motivo náo é apresentado neste trabalho.

Verifica-se que o desempenho dos monitores foi muito apreciado pelos estudantes, chegando ao ponto de $69 \%$ (22) dos estudantes afirmarem que gostariam de ser monitores no futuro.

Esse resultado não indica que não haja necessidade de se fazerem modificaçōes nos próximos anos. Os monitores e os estudantes registraram algumas sugestðes que deverão aperfeiçoar a dinámica do sistema de monitoria. 
Tabela 1 - Número de estudantes e respectivas respostas às questões de avaliação sobre os monitores.

\section{Avaliação}

\section{No de Respostas}

Positivas Negativas Sem

Resposta

\section{Total}

1. 0 monitor parece estar bem preparado para auxiliar o estudante a elucidar aspectos menos claros .

2. Os monitores demonstram paciEncia ao lidarem com os estudantes $\ldots \ldots \ldots \ldots \ldots \ldots \ldots$

3. O estudante sente-se à vontade para discutir com o monitor ....

31

30

$\begin{array}{llll}30 & 1 & 1 & 32\end{array}$

$1 \quad 1$

4. Gostaria de ser monitor futuramente ...............

Total .. 22

\begin{tabular}{rrr}
9 & 1 & 32 \\
\hline 12 & 3 & 128
\end{tabular}

Nos próximos anos manter-se-á a forma de seleção, uma vez que os três monitores acharam-na adequada, assim como as diretrizes básicas adotadas. Pretende-se, contudo, aperfeiçoar as atividades de pesquisa dos monitores e o ensino junto aos estudantes, desenvolver os mecanismos de comunicação docente-monitor e estimular os estudantes a fazerem melhor uso do Laboratório de Enfermagem.

FRIEDLANDER, M. R. Students as proctors: a experience in Fundamental of Nursing. Rev. Esc. Enf. USP, São Paulo 18(2):113-120, 1984.

Three advanced students were used as proctors in Fundamentals of Nursing for the academic periods of 1981 and 1982. Results are presented and the opinions of both, the proctors and oriented students, are discussed.

\section{REFERÊNCIAS BIBLIOGRÁFICAS}

- BLOOM, B. New views of the learn: implications for instruction and curriculum. Educational Leadership: 563-76, Apr. 1978.

- DONOHUE, J.; LITZ, K. SCOTT, S. PSI : an innovative approach to teaching nursing technologies. Journal of Nursing Education, 15(4):7, July 1976.

- HOGSTEL, M. D. A system for personalized instruction. Nursing Outlook, 24:110-4, 1976. 


\section{AVALIAÇĀO DA ATIVIDADE DO MONITOR EM FUNDAMENTOS DE ENFERMAGEM}

Nome do Monitor:

Periodo de Monitoria de a

Parte 1 - Orientaçăo: Para cada afirnaçắo que sogue, faça um ' $\mathrm{X}$ ' na coluna que corresponder à sua opinito.

No Pouco Razodvel Muito

1. A monitoria foi uma atividade agradável.

2. Se tivesse oportunidade voltaria a ser monitor.

3. A atividade desempenhada quando monitor prejudicou meu aproveitamento nas disciplinas que cursei paralelamente.

4. O tempo que dediquei à monitoria poderia ser mais bem aproveitado em outra ativi. dade.

5. A atividade dosempenhada como monitor, satisfoz minhas expectativas.

6. A atividade desempenhada como monitor, contribuiu para reforçar meus conhecimentos.

7. Encontrava-me preparado para as tarefas que realizei como monitor.

8. A monitoria deu-me oportunidade para desenvolver minha capacidade de ensinar.

9. A monitoria deu-mo oportunidade para eu me relacionar com estudantes de outras elasees.

Comentários relacionados às respostas dades:

Parte $H$ - Orientaģo - Seja objetivo e sincero nas respostas das questóes seguintes:

1 - Quais as tarefas da monitoria que the pareceram mais proveitoses para seu desenvolvimento pessoal

2 - Indique as vantagens de ser monitor.

3 - Indique as desvantagens de ser monitor. 
4- $O$ que the parece deva ser alterado na monitoria em Fundamentos de Enfermagem?

4-O que the parece deva ser alterado na monitoria em Fundamentos de Enfermagem? 